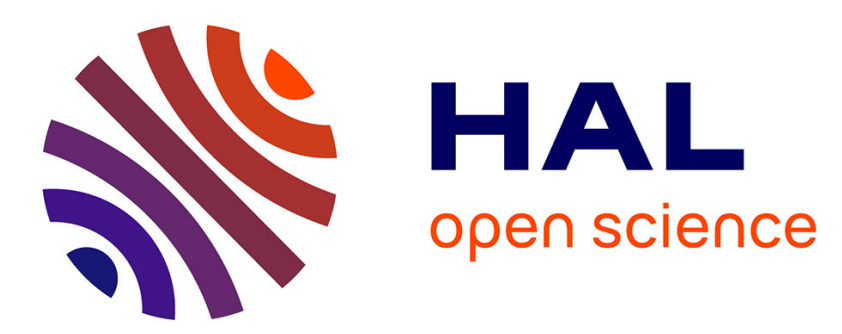

\title{
Extra large pore opening CFI and DON-type zeosils for mechanical energy storage
}

\author{
Laura Ronchi, Andrey Ryzhikov, Habiba Nouali, T. Jean Daou, Sébastien
}

Albrecht, Joël Patarin

\section{> To cite this version:}

Laura Ronchi, Andrey Ryzhikov, Habiba Nouali, T. Jean Daou, Sébastien Albrecht, et al.. Extra large pore opening CFI and DON-type zeosils for mechanical energy storage. Microporous and Mesoporous Materials, 2018, 255, pp.211-219. 10.1016/j.micromeso.2017.07.039 . hal-03544602

\author{
HAL Id: hal-03544602 \\ https://hal.science/hal-03544602
}

Submitted on 26 Jan 2022

HAL is a multi-disciplinary open access archive for the deposit and dissemination of scientific research documents, whether they are published or not. The documents may come from teaching and research institutions in France or abroad, or from public or private research centers.
L'archive ouverte pluridisciplinaire HAL, est destinée au dépôt et à la diffusion de documents scientifiques de niveau recherche, publiés ou non, émanant des établissements d'enseignement et de recherche français ou étrangers, des laboratoires publics ou privés. 


\title{
Extra large pore opening CFI and DON-type zeosils for mechanical energy storage
}

\author{
Laura Ronchi ${ }^{\mathrm{a}}$, Andrey Ryzhikov ${ }^{\mathrm{a}}$, Habiba Nouali ${ }^{\mathrm{a}}$, T. Jean Daou ${ }^{\mathrm{a}}$, Sébastien Albrecht ${ }^{\mathrm{b}}$, \\ Joël Patarin ${ }^{a}$ " \\ a Université de Strasbourg (UDS). Université de Haute Alsace (UHA), Axe Matériaux à Pornsité Contrôlée (MPC), Instirnt de Science des Matériaux de \\ Mulhouse (IS2M), UMR CNRS 7361, 3 bis rue Alfred Werner, F-68093 Mulhouse, France \\ "Université de Strashourg (UDS), Université de Haute Akace (UHA). Laboratoire de Chimie Organique et Bioorganique (COB), EA 4566, ENSCMu, F-68093 \\ Mulhouse, Frunce
}

\section{A B S T R A C T}

The energetic performances of pure silica CFI and DON-type zeolites (zeosils) were studied by intrusionextrusion experiments in water and $\mathrm{LiCl}$ aqueous solutions at different concentrations. For both zeosils, characterized by a 1D channel system with 14 MR pore openings, when water is used as nonwetting liquid a perfect reversible spring behavior is observed with an intrusion pressure of 75 and $26 \mathrm{MPa}$, respectively. The lower value for the DON-type structure is probably due to a larger pore aperture. The intrusion pressures in both cases rise considerably with the LiCl concentration, but the doubling of the salt concentration from 10 to $20 \mathrm{M}$ leads only to a slight increase of the intrusion pressure. The maximal stored energy achieves 14.6 and $6.8 \mathrm{~J} / \mathrm{g}$ for CF and DON-type zeosil-based systems, respectively. The zeolite samples were characterized before and after intrusion-extrusion experiments by XRD, SEM, $\mathrm{N}_{2}$ adsorption-desorption, TG and NMR analysis in order to get a better understanding of the influence of these intrusion-extrusion experiments on the CFI and DON-type structures.

\section{Introduction}

Zeolites are crystalline microporous solids widely used in adsorption, molecular separation, ion-exchange and catalysis processes [1]. In 2001 a peculiar application has been developed by our group for pure silica zeolites (zeosils) in the energy field [2]. Indeed the hydrophobic character of these materials is exploited for mechanical energy storage and dissipation by forcing the intrusion of water inside the pores of these solids under high pressure. During the penetration into the pores (intrusion), the supplied mechanical energy is converted into solid-liquid interfacial energy. Depending on the particular features of the considered zeosil (dimensionality of the porous system, type of porosity (channel or cage), presence of defects, ...), when the pressure is released (extrusion) the "zeosilwater" system can restore, dissipate or absorb the supplied energy showing, therefore a spring, a shock-absorber or a bumper behavior. Various "zeosil-water" systems have already been studied

- Corresponding author.

E-mail address: joel.patarin uha.fr (J. Patarin). by our group [2-4] and a relationship between the type of porosity and the intrusion pressure was established [5].

In recent years, it has been proved that replacing water with electrolyte solutions leads to an increase of the intrusion pressure, improving therefore the energetic performances of the corresponding "zeolite-nonwetting liquid" system [6-12]. For instance, the intrusion pressure can be enhanced by 7.4 times using a $20 \mathrm{M}$ $\mathrm{LiCl}$ aqueous solution instead of pure water on a LTA-type zeosil based system [7].

In this work and for the first time a focus is made on the energetic performances of pure silica CFI and DON-type zeolites with extra-large pore openings (hereafter, Si-CF and Si-DON). They are both characterized by a one-dimensional (1D) channel system with 14 MR (membered ring) openings $[13,14]$. The first one ever synthesized was UID-1 (DON-type) [14] using the organometallic complex (bis (pentamethylcyclopentadienyl)cobalt(III)) hydroxide, $\left[\left(\mathrm{Cp}^{*}\right)_{2} \mathrm{Co}\right] \mathrm{OH}$ as structure-directing agent. In the following years other high silica extra-large pore zeolites were synthesized such as CIT-5 (CFI-type) [13,15], SSZ-53 (SFH-type) [16] and SSZ-59 (SFNtype) [16]. These zeolites were developed to extend the research in the adsorption and catalysis fields [13,16]. 
Until now, various one-dimensional channel-type zeosils (AFI, MTT, MTW and TON) $[3,17]$ with smaller pore openings (10 or $12 \mathrm{MR}$ ) were tested for water intrusion. An interesting remark is that despite a formal smaller pore opening (12 MR), the AFI-type zeosil displays a pore aperture similar to the CF-type one $\left(7.3 \times 7.3 \AA^{2}\right)$ and $\left(7.2 \times 7.5 \AA^{2}\right)$, respectively [18]. This feature makes the comparison of the "AFI and CFI-water" systems interesting. The pore size of the DON-type zeosil is larger $\left(8.1 \times 8.2 \AA^{2}\right)$.

In the present work, the energetic performances of the "Si-CFInonwetting liquid" and Si-DON-nonwetting liquid" systems are reported. Water and $\mathrm{LiCl}$ aqueous solutions at two different concentrations ( $10 \mathrm{M}$ and $20 \mathrm{M}$ ) are chosen as nonwetting liquids. The samples were fully characterized before and after intrusionextrusion experiments by powder X-ray diffraction, Scanning Electron Microscopy, thermal analysis, $\mathrm{N}_{2}$ adsorption-desorption and solid-state NMR spectroscopy in order to study the influence of these experiments on the zeosil structures.

\section{Experimental section}

\subsection{Synthesis of Si-CFI and Si-DON samples}

The Si-CFI sample was synthesized in fluoride medium according the procedure published by Barrett et al. [13] using N-methyl(-)-sparteinium in the hydroxide form as structure-directing agent $(\mathrm{SDA}(\mathrm{OH}))$. The reactants used were: tetraethylorthosilicate (Evonik) as silica source, $\mathrm{SDA}(\mathrm{OH})$ (homemade synthesis, see Supporting Information) and $\mathrm{HF} \geq 40 \mathrm{wt} \%$ (Sigma-Aldrich). The starting gel (molar composition: $1 \mathrm{SiO}_{2}$ : $0.5 \mathrm{SDA}(\mathrm{OH}): 0.5 \mathrm{HF}: 15 \mathrm{H}_{2} \mathrm{O}$ ) was introduced in a Teflon-lined stainless-steel autoclave and heated at $175^{\circ} \mathrm{C}$ during 11 days under stirring at $60 \mathrm{rpm}$. After synthesis, the product was filtered, washed with distilled water and ethanol, then dried in an oven at $70{ }^{\circ} \mathrm{C}$ overnight. At the end, the solid was calcined at $650^{\circ} \mathrm{C}$ under air for $3 \mathrm{~h}$ to completely remove the organic template.

The Si-DON sample was synthesized according to an adapted procedure published by Freyhardt et al. [14] using $\left[\left(\mathrm{Cp}^{*}\right)_{2} \mathrm{Co}\right] \mathrm{OH}$ as structure-directing agent $(\mathrm{SDA}(\mathrm{OH}))$. The reactants used were: fumed silica (Cab-O-Sil M5) as silica source, $\mathrm{NaOH}>97$ wt \% (Carlo Erba) and bis(pentamethylcyclopentadienyl)cobalt(III) hexafluorophosphate (Alfa Aesar, 98\%) as SDA in its hydroxide form (see Supporting Information). The starting gel (molar composition: 1 $\mathrm{SiO}_{2}: 0.13 \mathrm{SDA}(\mathrm{OH}): 0.09 \mathrm{NaOH}: 57 \mathrm{H}_{2} \mathrm{O}$ ) was introduced in a Teflon-lined stainless-steel autoclave and heated at $150{ }^{\circ} \mathrm{C}$ during 14 days. After synthesis, the product was filtered, washed with distilled water and ethanol, then dried in an oven at $70^{\circ} \mathrm{C}$ overnight. In order to remove the organometallic template, the solid was previously calcined at $550^{\circ} \mathrm{C}$ under air for $6 \mathrm{~h}$, then treated with a $12 \mathrm{M} \mathrm{HCl}$ aqueous solution for $2 \mathrm{~h}$ at room temperature and afterwards with a $7 \mathrm{M} \mathrm{HCl}$ one at $50^{\circ} \mathrm{C}$ overnight.

\subsection{Intrusion-Extrusion experiments}

The intrusion-extrusion of water and $\mathrm{LiCl}$ aqueous solutions was performed at room temperature using a Micromeritics mercury porosimeter (Model Autopore IV), as described in a previous work [19].

Prior to the analyses, the Si-CF and Si-DON samples (nonintruded and intruded-extruded ones) were hydrated in a $80 \%$ relative humidity atmosphere for $24 \mathrm{~h}$ in order to set the hydration state

\subsection{Powder X-ray diffraction}

Powder X-ray diffraction patterns of the different samples were recorded on a STOE STADI-P diffractometer in the transmission scan mode equipped with a curved germanium (111), primary monochromator and a linear position-sensitive detector $\left(6^{\circ} 2 \theta\right)$ using $\mathrm{CuK} \alpha_{1}$ radiation $(\lambda=0.15406 \mathrm{~nm})$. Measurements were achieved for $2 \theta$ angle values in the $3-50^{\circ}$ range step $0.2^{\circ} 2 \theta$ and time $/$ step $=10 \mathrm{~s}$.

\subsection{Scanning electron microscopy}

The size and the morphology of the crystals were determined by scanning electron microscopy (SEM) using a Philips XL 30 FEG microscope.

\subsection{Nitrogen Adsorption-Desorption measurements}

Nitrogen adsorption-desorption isotherms were performed at $77 \mathrm{~K}$ using a Micromeritics ASAP 2420 apparatus. Prior to the adsorption measurements, the nonintruded sample were outgassed at 90 or $300{ }^{\circ} \mathrm{C}$ overnight under vacuum. The intruded-extruded samples were outgassed at $90^{\circ} \mathrm{C}$ overnight to avoid the dehydroxylation process. The specific surface area and microporous volume $\left(\mathrm{V}_{\text {micro }}\right)$ were calculated using the BET and $\mathrm{t}$-plot methods, respectively.

\subsection{Thermal analysis}

Thermogravimetric (TG) analyses were carried out on a Mettler Toledo STARe apparatus, under air flow, with a heating rate of $5^{\circ} \mathrm{C} /$ min from 30 to $800^{\circ} \mathrm{C}$.

\subsection{Solid-state NMR spectroscopy}

${ }^{29}$ Si MAS and ${ }^{1} \mathrm{H}-{ }^{29}$ Si CPMAS NMR spectra were recorded at room temperature on a Bruker Advance II $300 \mathrm{MHz}$ spectrometer, with a double-channel $7 \mathrm{~mm}$ Bruker MAS probe. The recording conditions are given in Table 1 .

\section{Results and discussion}

\subsection{Intrusion-extrusion experiments}

For all the systems, three intrusion-extrusion cycles were performed. For clarity only the first two cycles are presented, because all the cycles are superimposable. The $0-5 \mathrm{MPa}$ range on the pressure-axis is not shown, since the observed volume variation is due to the intrusion of the nonwetting liquid in the interparticular porosity of the zeosil pellet, as already mentioned in our previous work [4].

Table 1

Recording conditions of the $e^{29}$ Si MAS and ${ }^{1} \mathrm{H}^{29} \mathrm{Si}$ CPMAS NMR spectra.

\begin{tabular}{lll}
\hline & ${ }^{20}$ Si MAS & ${ }^{1} \mathrm{H}^{20}$ Si CPMAS \\
\hline Chemical Shift Standard & $\mathrm{TMS}^{2}$ & $\mathrm{TMS}^{2}$ \\
Frequency $(\mathrm{MHz})$ & 59.6 & 59.6 \\
Pulse width $(\mu \mathrm{s})$ & 2.3 & 5.0 \\
Flip angle & $\pi / 6$ & $\pi / 2$ \\
Contact time $(\mathrm{ms})$ & $/$ & 1 \\
Recycle time $(\mathrm{s})$ & 80 & $\mathrm{~b}_{3}$ \\
Spinning rate $(\mathrm{kHz})$ & 4 & 4 \\
Scans number & 1500 & 15,000 \\
\hline
\end{tabular}

Tetramethylsilane

Tetramethylsilane
The relaxation time $t_{i}$ was op timized. 
3.1.1. "Si-CF-nonwetting liquid" system

The pressure-volume diagrams of the "Si-CF-water" and "SiCF-LiCl aqueous solutions" systems are shown in Fig 1. The corresponding characteristic data are reported in Table 2 .

The pressure-volume diagrams depicted in Fig. 1 show that for the "Si-CF-water" system the intruded liquid at $75 \mathrm{MPa}$ is completely expelled at the same pressure from the porous matrix when the pressure is released. This indicates that the system is a perfect spring that can store and restore an energy of $6.0 \mathrm{~J} / \mathrm{g}$ over several cycles. The intruded volume $(0.08 \mathrm{~mL} / \mathrm{g})$ is lower than the porous volume determined by $\mathrm{N}_{2}$ adsorption-desorption measurements $\left(0.13 \mathrm{~cm}^{3} / \mathrm{g}\right.$, see Table 3$)$, but the difference is consistent with the one previously found for Silicalite-1 by Desbiens et al. [20]. where the water density inside the zeolite porosity must be corrected at 0.6 instead of the usual 1.0 .

Comparing the energetic performances of the "Si-CFl-water" system with the ones of other "one-dimensional channel-type zeosil-water" systems (AF, MTT, MTW and TON) [3,17], the same spring behavior is found. The absence of hysteresis between the intrusion and extrusion curves would indicate avery low amount of defect sites (dangling - $\mathrm{OH}$ groups) in the intruded-extruded samples as confirmed from TG and NMR analysis.

A previous work showed that the intrusion pressure is determined by the pore window diameter for channel-type zeosils and by the cage diameter for cage-type ones [5]. When intruded with water, TON and MTT-type zeosils, which are characterized by a 10 MR pore opening with similar diameter, show very high intrusion pressure values (186 and $176 \mathrm{MPa}$, respectively) [3,17]. For zeosils with larger pore openings (12 MR) such as AFI and MTWtype zeosils, water molecules can be more easily intruded into the porosity at 58 and $126 \mathrm{MPa}$, respectively [3]. The huge difference between the latter values is ascribed to the peculiar large dimension of AF-type zeosil pore opening. $\left(7.3 \times 7.3 \AA^{2}\right)$ compared to MTW one $\left(5.6 \times 6.0 \AA^{2}\right)$. Since the AF-type zeosil pore opening is similar to the Si-CF-type one $\left(7.2 \times 7.5 \AA^{2}\right)$, as expected, the intrusion pressure is observed in the same pressure range (58 and $75 \mathrm{MPa}$, respectively).

The increase of the LiCl concentration leads to an increase of the intrusion pressure (75, 147 and $162 \mathrm{MPa}$ for water, $10 \mathrm{M}$ and $20 \mathrm{M}$
$\mathrm{LiCl}$ aqueous solutions, respectively). Several hypotheses have been proposed to explain such a phenomenon: i) a higher solid-liquid interfacial tension of electrolyte aqueous solution in comparison with water $[21,22]$, ii) an osmotic phenomenon $[23,24]$, iii) a confinement effect of the nanopore walls [10] or iv) a ion desolvation phenomenon $[6,25]$. A recent study, dealing with the "FERtype zeosil- $\mathrm{MgCl}_{2} \cdot 21 \mathrm{H}_{2} \mathrm{O}$ " system demonstrated that the electrolyte aqueous solution intruded into the pores is more concentrated $\left(\mathrm{MgCl}_{2}, 10 \mathrm{H}_{2} \mathrm{O}\right)$ than the initial one. The decrease of the water content and, thus, the higher concentration of the intruded solution could be reasonably the result of the hydrophobic nature of the host zeolite matrix [26].

It can be interesting to compare the intrusion pressure values with those obtained for the systems based on 3D channel-type zeosils. A linear increase (96, 193 and $285 \mathrm{MPa}$ for water, $10 \mathrm{M}$ and $20 \mathrm{M} \mathrm{LiCl}$ aqueous solutions, respectively) was observed for the MFl-type zeosil (10 MR) [9], while for the *BEA-type (12 MR) [8] the increase between water and $10 \mathrm{M} \mathrm{LiCl}$ aqueous solution is more important than the one between $10 \mathrm{M}$ and $20 \mathrm{M} \mathrm{LiCl}$ aqueous solutions (53, 95 and $115 \mathrm{MPa}$ for water, $10 \mathrm{M}$ and $20 \mathrm{M} \mathrm{LiCl}$ aqueous solutions, respectively). The same trend than in latter case is observed for the "Si-CFl-nonwetting liquid" systems. This is probably related to the larger pore opening of "BEA-type and CFI-type zeosils that oppose less resistance to the liquid.

For "Si-CFI-LiCl aqueous solutions" systems, the spring behavior with an energy yield of $97 \%$ is maintained, but a slight hysteresis is visible. This trend was already observed for MFI-type zeolite [9]. The rise of the intrusion pressure with $\mathrm{LiCl}$ aqueous solutions leads to an increase of the stored energy (6.0, 13.2 and $14.6 \mathrm{~J} / \mathrm{g}$ for water, $10 \mathrm{M}$ and $20 \mathrm{M} \mathrm{LiCl}$ aqueous solutions, respectively). Such energy values are relatively low compared to MFI-based systems ( $31 \mathrm{~J} / g$ with $20 \mathrm{M} \mathrm{LiCl}$ aqueous solution).

\section{1. "Si-DON-nonwetting liquid" system}

The P-V diagrams of the "Si-DON-nonwetting liquid" systems are reported in Fig. 2 and the corresponding data in Table 2. Compared to the "Si-CF-nonwetting liquid" system and whatever the nonwetting liquid, the intrusion step is less steep (Fig. 2). An important spread is observed particularly for the LiCl-based

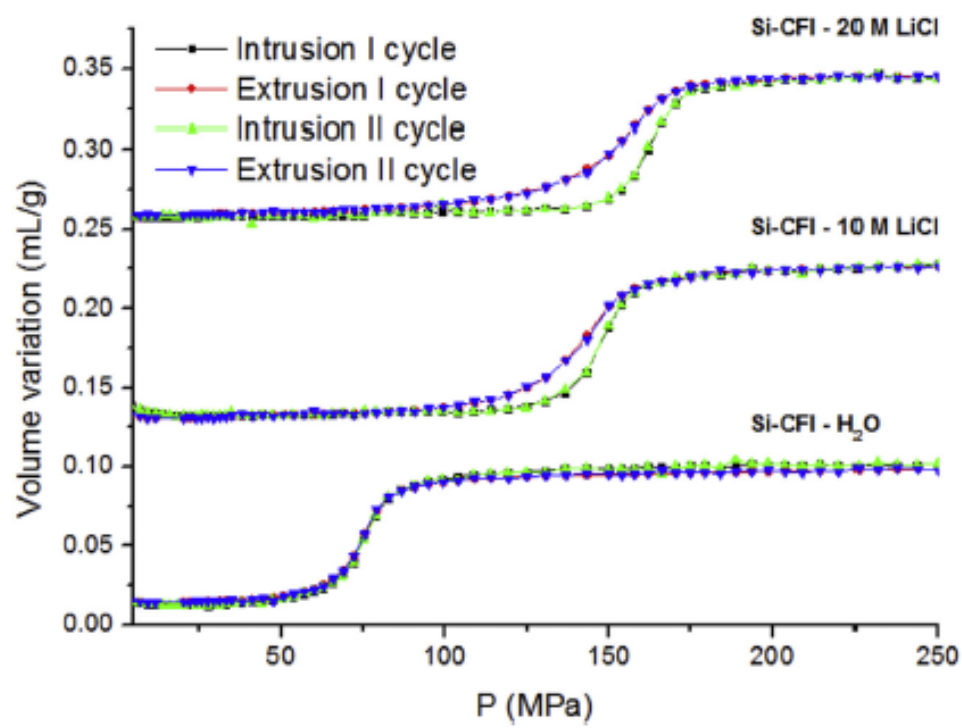

Fig 1. First and second intrusion-extrusion cydes of the "Si-CFF-water" and "Si-CF-LiCl aqueous sol utions" systems For clarity, the intrusion-extrusion isotherms are shifted along the $Y$ axis. 
Table 2

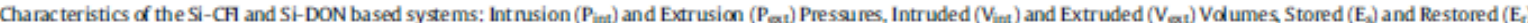
列 intrusionextrusion cycles.

\begin{tabular}{|c|c|c|c|c|c|c|c|}
\hline System & $\mathrm{P}_{\text {imt }}[\mathrm{MPa}]^{2}$ & $\mathrm{P}_{\mathrm{at}}[\mathrm{MPa}]^{4}$ & $\mathrm{~V}_{\text {imt }}[\mathrm{ml} / \mathrm{g}]^{a}$ & $\mathrm{~V}_{e x e}[\mathrm{ml} / \mathrm{g}]^{d}$ & $\mathrm{E}_{\mathrm{a}}[\mathrm{J} / \mathrm{g}]^{\mathrm{b}}$ & $\mathrm{E}_{\mathrm{B}}[\mathrm{L} / \mathrm{g}]^{\mathrm{r}}$ & Energy Yield $(x)$ \\
\hline $\mathrm{Si}-\mathrm{CFI}-\mathrm{H}_{2} \mathrm{O}$ & 75 & 75 & 008 & 0.08 & 6.0 & 6.0 & 100 \\
\hline Si-CFI - $10 \mathrm{M} \mathrm{LICI}$ & 147 & 143 & 009 & 0.09 & 13.2 & 129 & 97 \\
\hline Si-CFI - 20 M LIG & 162 & 158 & 009 & 0.09 & 14.6 & 142 & 97 \\
\hline Si-DON - $10 \mathrm{M} \mathrm{LIC}$ & 81 & 70 & 006 & 0.06 & 4.9 & 4.2 & 86 \\
\hline Si-DON - $20 \mathrm{M}$ LiC & 85 & 75 & 008 & 0.08 & 6.8 & 6.0 & 88 \\
\hline
\end{tabular}

Determined from intrusion-extrusion curves.

$\checkmark$ Stored energy $E_{d}-V_{\text {int }} \times P_{\text {int }}$

$\leftarrow$ Restored energy $\mathrm{E}_{4}-\mathrm{V}_{\text {ex }} \times \mathrm{P}_{\text {ex }}$

¿Energy yield $\left(x^{2}\right)-\mathrm{E}_{t} / \mathrm{E}_{\mathrm{s}} \times 100$

systems. For instance, the intrusion starts around $25 \mathrm{MPa}$ with a complete filling of the pores at around $150 \mathrm{MPa}(20 \mathrm{M} \mathrm{LiCl})$. The crystal morphology (packed needles) might be responsible of the spreading in pressure as previously observed for the TON-type zeosil [3]. However, in all cases a spring behavior is mainly observed with a slight hysteresis between the intrusion and extrusion curves for the "Si-DON-20 M LiCl aqueous solution" system. Although both CF and DON-type zeosils display a 1D channel system with 14 MR openings, the intrusion pressures for the Si-DON-based systems are strongly lower (from 26 to $85 \mathrm{MPa}$, see Table 2). Such a result is not so surprising since the pore apertures of the DON-type structure are larger (see introduction section).

The intruded volumes with water and $10 \mathrm{M} \mathrm{LiCl}$ aqueous solutions ( 0.04 and $0.06 \mathrm{~mL} / \mathrm{g}$, respectively) are quite low compared to the microporous volume found by $\mathrm{N}_{2}$ adsorption-desorption measurements $\left(0.15 \mathrm{~cm}^{3} / \mathrm{g}\right.$ see below) and cannot be explained only by the lower density of water confined in the nanopores of the zeolite. Another explanation could be the partially spontaneous intrusion of the liquid inside the porous matrix at low pressure (in the nonreported 0-5 MPa range, see above). For the $20 \mathrm{M} \mathrm{LiC}$ aqueous solution, the intruded volume is higher $(0.08 \mathrm{~mL} / \mathrm{g})$ revealing thus a non intrusion of this liquid at low pressure. A similar evolution of intruded volume with $\mathrm{LiCl}$ concentration was previously observed in the case of high-silica $(\mathrm{Si} / \mathrm{Al}=110$ ) FAU-type zeolite with partially hydrophobic pores [27]. Unfortunately, despite the large pore openings the stored energy for "Si-DONnonwetting liquid" systems are low and ranging from 1.0 to $6.8 \mathrm{~J} / \mathrm{g}$

\section{XRD and SEM characterizations}

The XRD patterns of the different Si-CF and Si-DON samples are reported in Figs. 3 and 4 , respectively. For both zeosils no significant changes are observed before and after intrusion-extrusion experiments. This indicates that at the long-range order the structures are not affected by the high pressure experiments.

The Si-CF and Si-DON samples were al so examined by Scanning Electron Microscopy, before and after the intrusion-extrusion cycles. The crystals of the nonintruded Si-CF sample (Fig. 5a) display a rod shape morphology with dimensions of $\sim 10 \times 0.7 \times 0.7 \mathrm{um}^{3}$

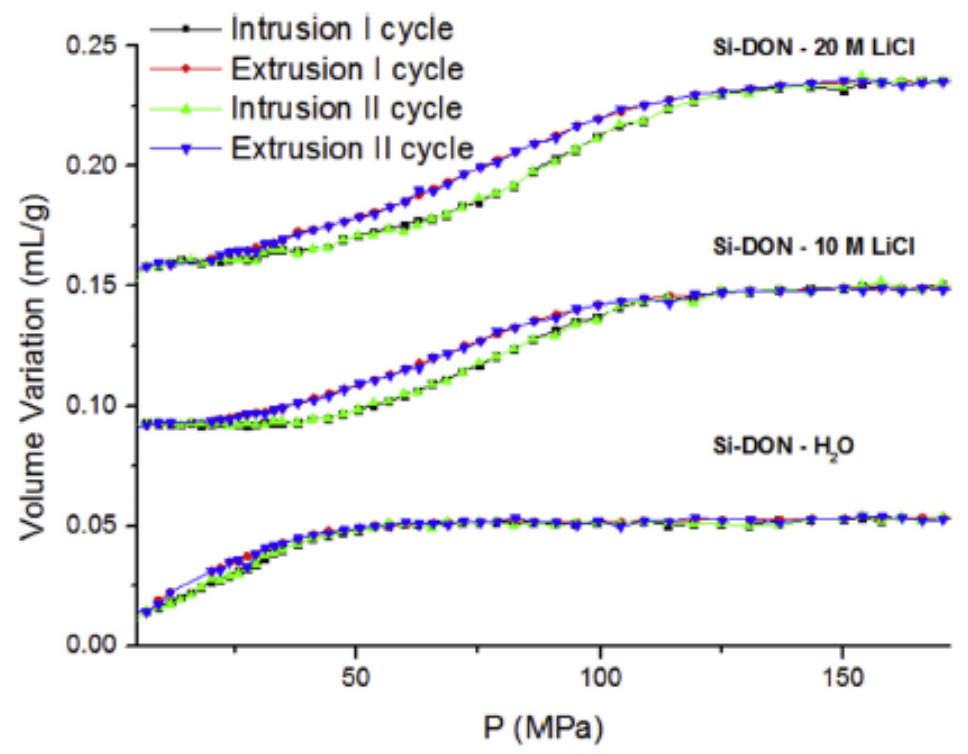

Fig. 2 First and second intrusion-extrusion cycles of the "Si-DON-water" and "Si-DON-LCl aqueous solutions" systems For clarity, the intrusion-extrusion isotherms are shifted along the $Y$ axis. 


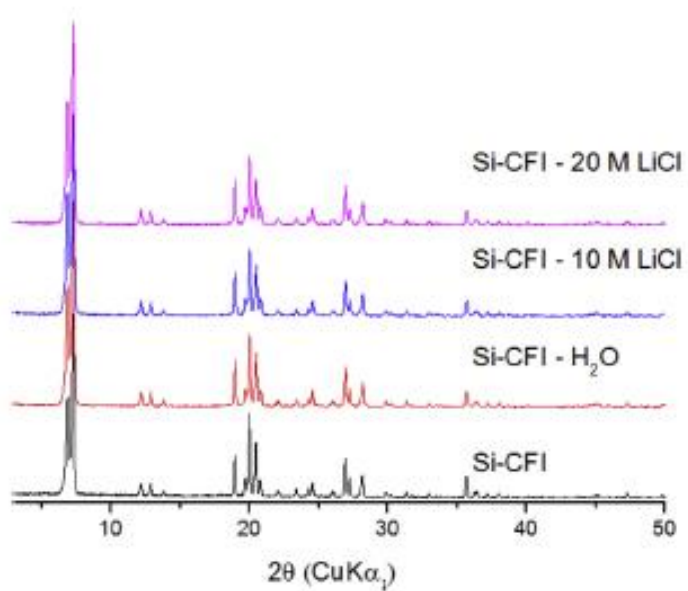

Fig 3 XRD pattems of SI-CH samples before and after three intrusion-extrusion cycles in water, $10 \mathrm{M}$ and $20 \mathrm{M}$ LCCl aqueous solutions.

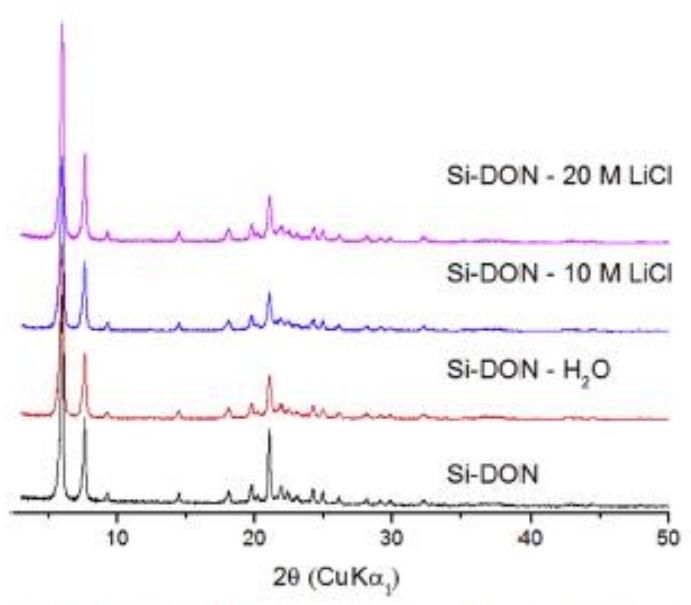

Fig. 4 XrD partems of Si-DON samples before and after three intrusion-extrusion cycles in water, $10 \mathrm{M}$ and $20 \mathrm{M} \mathrm{LiCl}$ aqueous solutions.

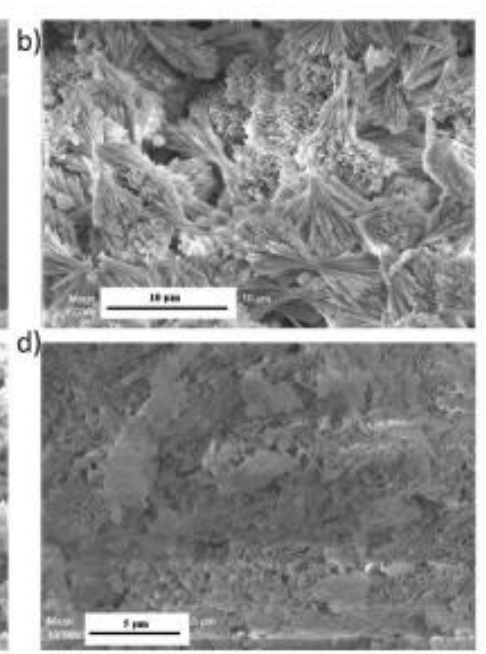

Fig. 5. SEM micrographs of S-CF and Si-DON samples before (a and b, respectively) and after three intrusion-extrusion cydes in water ( $c$ and d, respectively).

whereas those of Si-DON (Fig. 5b) consist in packed needles of dimensions of $-10 \times 0.2 \times 0.1 \mathrm{\mu m}^{3}$. In both cases and whatever the nature of the intruded liquid, after intrusion-extrusion experiments the crystals are broken (Fig. $5 c$ and d).

\section{3. $\mathrm{N}_{2}$ adsorption-desorption isotherms}

\subsubsection{Si-CFI samples}

The $\mathrm{N}_{2}$ adsorption-desorption isotherms of the nonintruded and intruded samples are shown in Fig. 6. In all cases the isotherms are mainly of type I characteristic of microporous solids. The BET surface area and microporous volume $\left(\mathrm{V}_{\text {micro }}\right)$ of the nonintruded sample outgassed at $300{ }^{\circ} \mathrm{C}$ are $340 \mathrm{~m}^{2} / \mathrm{g}$ and $0.130 \mathrm{~cm}^{3} / \mathrm{g}$ respectively, that are similar to the values reported in the literature [13]. After an outgassing at $90^{\circ} \mathrm{C}$, a lower surface area $\left(245 \mathrm{~m}^{2} / \mathrm{g}\right.$. and a lower microporous volume are observed $\left(0.095 \mathrm{~cm}^{3} / \mathrm{g}\right)$ revealing thus the presence of remaining physisorbed water in the nonintruded sample. After intrusion-extrusion experiments, the pore volume and surface area are considerably lower (see Table 3). All these results are quite in agreement with the TG curves since for all the samples the end of the first weight loss is observed at $150-200^{\circ} \mathrm{C}$ and this weight loss, in particular for the LiC aqueous solutions intruded samples, is larger for the intruded samples (see Fig. 7). The larger amount of physisorbed water in the intruded samples indicates the creation of few hydrophilic defects sites (-OH groups). However, after an outgassing at $300^{\circ} \mathrm{C}$ (see Supporting Information, Fig. S1), the microporous volume of the waterintruded sample $\left(0.12 \mathrm{~cm}^{3} / \mathrm{g}\right)$ is comparable with the one of the nonintruded solid confirming that no great damages are caused after intrusion under high pressure as confirmed by NMR spectroscopy. 


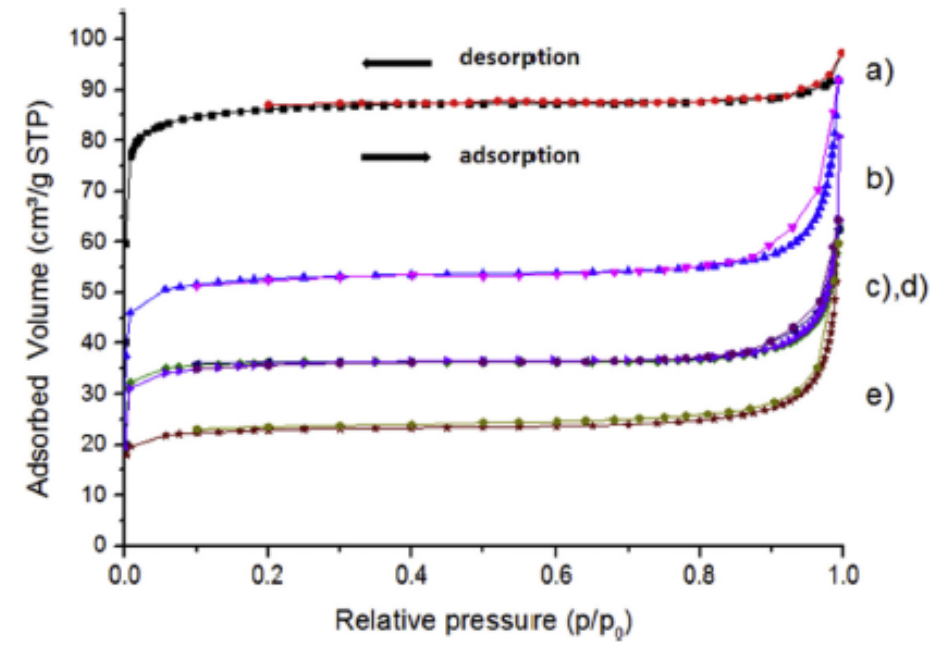

Fig. 6. $\mathrm{N}_{2}$ adsorption-desorption isotherms at $-196^{\circ} \mathrm{C}$ of the nonin truded $\mathrm{Si}-\mathrm{CF}$ samples out gassed at a) $300^{\circ} \mathrm{C}$ and b) $90^{\circ} \mathrm{C}$ and Si-CF samples outgassed at $90^{\circ} \mathrm{C}$ after intrusionextrusion in c) water, d) $10 \mathrm{M}$ and e) $20 \mathrm{M}$ LCl aqueous solutions

Table 3

Microporous volume $\left(\mathrm{V}_{\text {micro }}\right)$ and specific surface area $\mathrm{S}_{\mathrm{BET}}$ val ues obxained from $\mathrm{N}_{2}$ adsorption-desorption isotherms at - $196^{\circ} \mathrm{C}$ of $\mathrm{Si}$-CFl samples before and after intrusionextrusion experiments outgassed at 90 and $300^{\circ} \mathrm{C}$

\begin{tabular}{|c|c|c|c|c|c|}
\hline Outgassing temperature & $\begin{array}{l}\text { Si-CFI } \\
\left(300^{\circ} \mathrm{C}\right)\end{array}$ & $\begin{array}{l}\text { Si-CF } \\
\left(90^{\circ} \mathrm{C}\right)\end{array}$ & $\mathrm{Si}-\mathrm{CH}-\mathrm{H}_{2} \mathrm{O}\left(90^{\circ} \mathrm{C}\right)$ & Si-CH-10 M LCl $\left(90^{\circ} \mathrm{C}\right)$ & Si-CH-20 M LiC $\left(90^{\circ} \mathrm{C}\right)$ \\
\hline $\begin{array}{l}V_{\text {micre }}\left(\mathrm{cm}^{3} / \mathrm{g}\right) \\
S_{\text {fier }}\left(\mathrm{m}^{2} / \mathrm{g}\right)\end{array}$ & $\begin{array}{l}0.130 \\
343\end{array}$ & $\begin{array}{l}0.095 \\
245\end{array}$ & $\begin{array}{l}0.050 \\
125\end{array}$ & $\begin{array}{l}0.050 \\
120\end{array}$ & $\begin{array}{l}0.035 \\
95\end{array}$ \\
\hline
\end{tabular}

\subsubsection{Si-DON samples}

For all Si-DON samples, the $\mathrm{N}_{2}$ adsorption-desorption isotherms (see Supporting Information, Fig. S2) are mainly of type I and characteristic of microporous solids. The BET surface area and microporous volume of the nonintruded sample outgassed at $300{ }^{\circ} \mathrm{C}$ are $408 \mathrm{~m}^{2} / \mathrm{g}$ and $0.15 \mathrm{~cm}^{3} / \mathrm{g}$, respectively, while when outgassed at $90{ }^{\circ} \mathrm{C}$ they are $252 \mathrm{~m}^{2} / \mathrm{g}$ and $0.10 \mathrm{~cm}^{3} / \mathrm{g}$, respectively. Similar characteristic data are obtained for the intruded samples outgassed at $90^{\circ} \mathrm{C}$ whatever the nonwetting liquid. Therefore, as for the Si-CFI samples and in agreement with the TG analysis (see Supporting Information, Fig. S3), after an outgassing at $90^{\circ} \mathrm{C}$ the microporous volume found for the nonintruded and intruded samples $\left(0.095 \mathrm{~cm}^{3} / \mathrm{g}\right.$ in both cases $)$ can be ascribed to the presence of remaining physisorbed water.

\subsection{Thermogravimetric analysis}

\subsubsection{Si-CFI samples}

The experimental results issued from the thermogravimetric (TG) analysis of the Si-CF samples before and after intrusionextrusion experiments are depicted in Fig. 7. The high hydrophobic character is confirmed by the small total weight loss that ranges from $0.6 \mathrm{wt} \%$ for the nonintruded sample to $1.4 \mathrm{wt} \%$ for the samples intruded with $10 \mathrm{M}$ and $20 \mathrm{M} \mathrm{LiCl}$ aqueous solutions. The weight losses occur in two main steps. The first one, between 30 and $200{ }^{\circ} \mathrm{C}$, is ascribed to the desorption of physisorbed water molecules. The second one, in the temperature range of $200-800^{\circ} \mathrm{C}$, can be assigned to water arising from dehydroxylation reactions. The creation of defects (dangling $-\mathrm{OH}$ groups) during the intrusion-extrusion experiments is indicated by the increase of this second weight loss for the intruded samples and therefore the in crease of the number of $-\mathrm{OH}$ groups per unit cell $\left(\mathrm{Si}_{32} \mathrm{O}_{64}\right):-0.5$ for the nonintruded sample, -1.0 for the one intruded with water and -2.0 for the LiCl aqueous solution intruded ones. However, ac cording to the NMR results (see below), the number of - $\mathrm{OH}$ groups per unit cell is still quite low after intrusion-extrusion experiments.

\subsubsection{Si-DON samples}

Compared to the Si-CFI samples, the total weight loss for the SiDON samples is higher and ranges from 3.0 wt $\%$ for the nonintruded sample to 3.75 wt $\%$ for the sample intruded with $20 \mathrm{M}$ $\mathrm{LiCl}$ aqueous solution (see Supporting Information, Fig. S3). It also occurs in two main steps corresponding to the removal of physisorbed water molecules and the removal of water arising from dehydroxylation reactions. From the second weight loss, whatever the samples (intruded or nonintruded ones) about 8 -OH groups were found per unit cell $\left(\mathrm{Si}_{64} \mathrm{O}_{128}\right)$. From these results, it seems that the intrusion-extrusion experiments do not cause significant damages in the zeosil structure as confirmed by NMR spectroscopy (see below). 


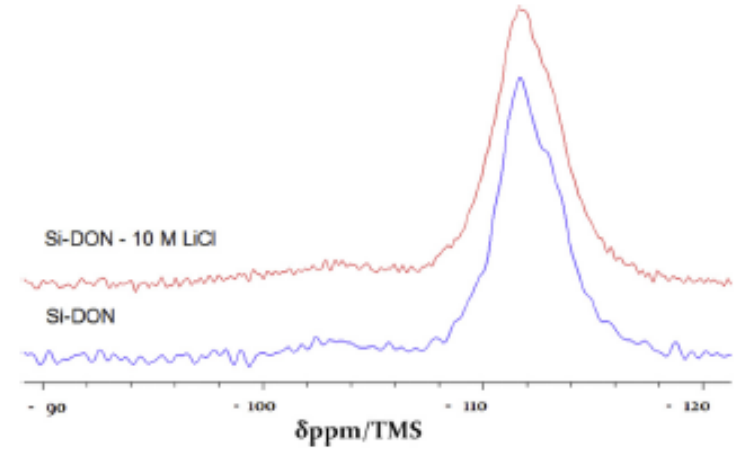

Fig.10 ESi-MAS NMR spectra of the Si-DON samples before and after three intrusionextrusion cycles in $10 \mathrm{M} \mathrm{LCl}$ aqueous solution.

at $-102.8 \mathrm{ppm}$ corresponding to $\mathrm{Q}_{3}$ species (silanol groups) is clearly detected in both spectra. Although the NMR spectrum of the nonintruded sample shows a lower signal/noise ratio, the number of defect sites does not seem to increase after intrusion-extrusion experiments which is in quite good agreement with the TG results (the number of $-\mathrm{OH}$ groups for these samples is about 0.5 and $2.0-\mathrm{OH}$ per unit cell).

\subsection{Si-DON samples}

The ${ }^{29}$ Si MAS NMR spectra of the Si-DON samples before and after intrusion-extrusion experiments with $10 \mathrm{M} \mathrm{LiCl}$ aqueous solution are shown in Fig. 10. In agreement with the literature [29], both spectra exhibit a very broad resonance between - 106.6 and $-119.2 \mathrm{ppm}$ ascribed to $\mathrm{Q}_{4}$ groups ( $\left.\mathrm{Si}-(\mathrm{OSi})_{4}\right)$ and corresponding to the five non-equivalent crystallographic silicon sites (orthorhombic symmetry) of the framework. Another smaller component, between -97.0 and $-106.5 \mathrm{ppm}$, attributable to $Q_{3}$ sites is also visible. It corresponds to about $7.0 \%$ of the total ${ }^{29} \mathrm{Si}$ signal, value in quite good agreement with the TG results $(8-\mathrm{OH}$ group per unit cell). From structural characterization of the calcined form of UTD-1, Lobo and coworkers $[14,29]$ showed that the structure was highly faulted and disordered along the onedimensional 14-ring channel. Such a disorder can explain the

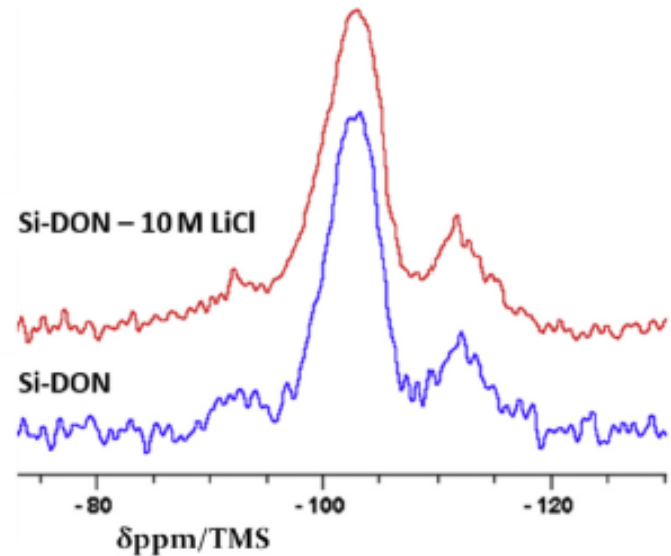

Fig. 11. ${ }^{1} \mathrm{H}^{2}{ }^{29} \mathrm{~S}$-CPMAS NMR spectra of the S-DON samples before and after three intrusion extrusion cycles in $10 \mathrm{M} \mathrm{LiCl}$ aqueous solution. presence of the broad $\mathrm{Q}_{4}$ component on the NMR spectra. No relevant differences can be found between the NMR spectra of the nonintruded and intruded samples. This indicates that at the shortrange order the zeolite structure is not affected after the intrusionextrusion experiments.

The corresponding ${ }^{1} \mathrm{H}^{2}{ }^{29} \mathrm{Si}$ CPMAS NMR spectra are shown in Fig 11. They are very similar and display three components with maxima at $-92.6,-103.5$ and $-112.6 \mathrm{ppm}$. The latter corresponds to $\mathrm{Q}_{4}$ groups while the former to $\mathrm{Q}_{2}\left((\mathrm{HO})_{2}-\mathrm{Si}-(\mathrm{OSi})_{2}\right)$ and $\mathrm{Q}_{3}(\mathrm{HO})$ $\mathrm{Si}-(\mathrm{OSi})_{3}$ ) groups. No significant difference is observed between these spectra which means that the impact of intrusion-extrusion experiments on the DON-type structure is very low.

\section{Conclusion}

The energetic performances of pure silica CFI- and DON-type zeolites were studied by intrusion-extrusion in water and LiCl aqueous solutions at different concentrations. These zeosils are characterized by a one-dimensional channel-system with extralarge pore openings (14 MR), the largest between all studied zeosils for energetic applications. As it was already observed for other water-intruded zeosils with 1D pore system (AF, MTT, MTW and TON), "Si-CF-water" and "Si-DON-water" systems show a spring behavior. Because of the larger pore size a quite low value of the intrusion pressure is observed ( 75 and $26 \mathrm{MPa}$, respectively) which is comparable with the one found for AFI-type zeosil based system ( $58 \mathrm{MPa}$ ) that have similar pore apertures. The lower value for the DON-type structure can be explained by a larger pore aperture. Using a $10 \mathrm{M} \mathrm{LiCl}$ aqueous solution, the intrusion pressure is considerably increased (147 and $81 \mathrm{MPa}$, respectively), while doubling the $\mathrm{LiCl}$ concentration only a slight increase is observed (162 and $85 \mathrm{MPa}$, respectively). The concentration increase does not affect the spring behavior of the system, but a slight hysteresis between the intrusion and extrusion curves is observed. The different characterization techniques show that intrusionextrusion experiments induce only a slight amount of defect sites in the zeosils structure. With water and $10 \mathrm{M} \mathrm{LiCl}$ aqueous solution, a low intruded volume is observed for DON-type zeosil that can be related with the partially hydrophilic character of its structure. Unfortunately, the stored energy for both CFI and DON-based systems are quite low: 14.6 and $6.8 \mathrm{~J} / \mathrm{g}$, respectively, for $20 \mathrm{M} \mathrm{LiCl}$ aqueous solution.

\section{Acknowledgements}

Laura Ronchi thanks the University of Haute Alsace (UHA) for their financial support for her Ph.D. grant. The authors would like to thank Ludovic Josien, Séverinne Rigolet and Laure Michel in for their assistance in scanning electron microscopy, NMR analyses and XRD measurements.

A special thank to Jean-Louis Paillaud and Minh Hang Au for the synthesis of SDA

\section{Appendix A. Supplementary data}

Supplementary data related to this article can be found at http:// dx.doi.org/10.1016/j.micromeso .2017.07.039.

\section{References}

[1] J. Čejka, H. Van Bekkum, A. Corma, F. Schüth, Stud, Surf. Sci, CataL. 168 (2007) $1-1047$.

[2] V. Eroshenka, R.C. Regis, M. Soulard, J. Patarin, J. Am. Chem. Soc, 123 (2001) $8129-8130$.

[3] L. Tzanis M. Trzpit, M. Soulard, J. Patarin, Microporous Mesoporous Mater 146 (2011) 119-126, 
[4] L Tzanis, B. Marler, H Gies I Patarin J Phys, Chem. C 117 (2013) 4098-4103, L. Tzanis, M. Trzpit, M. Soulard, J. Patarin, J. Phys Chem. C 116 (2012) $20389-20395$

[6] M. Soulard,J. Patarin, Pat Fr2976030 (2012)

[7] A. Ryzhikov, L. Ronchi, H. Nouali, T.J. Daou, J.-L. Paillaud, J. Patarin, J. Phys

[8] A. Ryzhikov, L Khay, H. Nouali, T.J. Daou, J. Patarin, Phys, Chem. Chem. Phys. 16 (2014) 17893-17899.

[9] I. Khay, TJ. Daou, H. Nouali, A. Ryzhikov, S. Rigolet, J. Patarin, J. Phys. Chem. C 118 (2014) 3935-3941.

10] A. Han, W. Lu, T. Kim, V.K. Punyamurtula, Y. Qjao, Smart Mater. Struct. 18 (2009) 24005 .

11] A. Han, Y. Qiao, J. Mater, Res, 22 (2007) 644-648

12] L Liu, X.Chen, W. Lu, A. Han, Y. Qiao, Phys, Rev, Lett. 102 (2009), 184501-1-4.

3] P.. Barrett, M.j. Diaz-Cabañas, M.A. Camblor, R.H. Jones, J. Chem. Soc. Faraday Trans. 94 (1998) 2475-2481.

14] C. Freyhardt, M. Tsapatsis, R.F. Lobo, KJ. Balkus, M.E. Davis, Nature 38 (1996) 295-298.

15] P. Wagner, M. Yoshikawa, K. TsujL, M.E. Davis P. Wagner, M. Lovallo, M. Taspatsis, Chem. Commun. (1997) 2179-2180.

16] A. Burton, S. Elomari, C-Y. Chen, R.C Medrud, L.Y. Chan, L.M. Bull, C Kibby, T.V. Harris, S.I. Zones, E.S Vittoratos Chem. - Eur. J. 9 (2003) 5737-5748.
[17] A. Ryzhikov, I, Khay, H, Nouali, T, Daou, J. Patarin. RSC Adv, 4 (2014) 37655-37661.

[18] http://europe iza-structure.org/ZA-SC/ftc tablephp

[19] M. Trzpit, M. Soulard, J. Patarin, Chem. Lett. 36 (2007) 980-981.

[20] N. Desbiens, L. Demachy, A.H. Fuchs, H. Kirsch-Rodeschini. M. Souland, J. Patarin, Angew. Chem. Int. Ed. 44 (2005) 5310-5313.

[21] E.W. Washbum. Proc. Natl, Acad. Sci. U. S. A. 7 (1921) 115-116.

[22] W. Peiming. A. Anderko, R.D. Young, Ind. Eng. Chem. Res. 50 (2011) 4086-4098.

[23] M. Michelin-jamois C Picand, E Chardaix and G. Vigier, ArXju:1404.5318v1 Physics.chem-Ph (2014) 1-4.

[24] M. Michelin-Jamois, C. Picard, G. Vigier, E. Charlaix, Phys Rev, Lett. 115 (2015) $036101 / 1-036101 / 4$

25] A. Han, V.K. Punyamurtula, Y. Q iaQ, Appl. Phys. Lett. 92 (2008), 153117-1-3. 6] R. Arletti, L. Ronchi, S, Quartieri, G. Vezzal ini, A. Ryzhikov, H. Nouali, T.J. Daou, J. Patarin, Microporous Mesoporous Mater 235 (2016) 253-260.

[27] A. Ryzhikov, L Khay, H. Nouali, T.J. Daou, J. Patarin, Microporous Mesoporous Mater 221 (2016) 1-7.

[28] M. Yoshikawa, P. Wagner, M. Lovallo, K. Tsuji, T. Takewaki, C-Y. Chen, LW. Beck, C Jones, M. Tsapatsis, S.L Zones, M.E. Davis, J. Phys. Chem. B 102 (1998) $7139-7147$.

[29] RF, Lobo, M. Tsapaksis, CC. Freyhardt, S, Khodabandeh, P. Wagner, C-Y, Chen, K.J. Balkus, S.I. Zones M.E. Davis, f. Am. Chem. Soc. 119 (1997) 8474-8484 